\title{
Obesity in Adults: A Neglected Public Health Problem in Urban Areas ofKandahar City, Afghanistan
}

\author{
Khwaja Mir Islam Saeed (MD, MSc) ${ }^{1}$ \\ ${ }^{1}$ Head of Grant and Service Contract Management Unit (GCMU), Ministry of Public Health, Kabul- \\ Afghanistan, Tel: 0093700290955
}

\begin{abstract}
Background:Obesity is a major public health problem particularly, for elderly, considered one of the most serious challenges all over the world. This study aims to determine the prevalence and risk factors of obesity among elders Kandahar city, Afghanistan.

Methods and Materials: Descriptive and analytical cross sectional study was conducted in Kandahar city within October-November, 2015. Multistage random sampling technique used and 1165 adults of 25-70 years were cleaned for analysis. WHO STEPS approach used to collect data on demographic and behavioral factors. Physical measurement comprising height, weight and blood pressure including blood samples were collected and tested for biochemical measurements including blood lipids. Descriptive and inferential analyses were performed using SPSS v.20.

Results: The prevalence of underweight, normal weight, overweight, obesity grade I, obesity grade II and obesity grade III were $4.9 \%, 44.8 \%, 34.3 \%, 11.2 \%, 2.9 \%$ and $1.9 \%$ respectively. Out of all respondents 597 $(51.2 \%)$ were females and $568(48.8 \%)$ males with a mean age of $38.3 \pm 11.2$ years. Around two thirds $(73.2 \%)$ were illiterates and $(79.3 \%)$ were married. $9.7 \%$ were smokers and $(16.3 \%)$ were mouth snuff users. The average of total cholesterol, glycerides, high density lipoprotein, low density lipoprotein and fast blood sugar were $183 \mathrm{mg} / \mathrm{DL}, 154.65 \mathrm{mg} / \mathrm{DL}, 45.85 \mathrm{mg} / \mathrm{DL}, 107.3 \mathrm{mg} / \mathrm{DL}$ and $131 \mathrm{mg} / \mathrm{DL}$ respectively. Age, sex, education status, walking, triglyceride level, high blood pressure and central obesity were independently associated with obesity.
\end{abstract}

Conclusion: Obesity is a cause of concern in urban citizens in Afghanistan. Increase awareness about obesity and healthy lifestyle is essential for adults to prevent obesity and its complications.

Key Words: Prevalence, Obesity, adults, risk factors, WHO Steps, Afghanistan

\section{INTRODUCTION}

Obesity is a complex condition contributing to chronic diseases by affecting virtually all ages and socioeconomic groups [1]. Obesity is said to be adversely affecting the structure and functions of the body and lowering overall quality of life [2]. Discrimination with respect to employment, education, healthcare and compensation to work are other social problems that obese and overweight adults will suffer from [3-4]. In 2010 , overweight and obesity were estimated to cause 3.4 million deaths, $4 \%$ of years of life lost, and $4 \%$ of disability-adjusted life-years (DALYs) [5]. With the use of Indo-Asian-specific Basic Mass Index (BMI) cutoff values the prevalence of overweight and obesity were $25 \%$ and $10.3 \%$ respectively [6]. In the Eastern Mediterranean Region obesity and overweight has reached an alarming level. The prevalence of obesity among adolescents ranges from $15 \%$ to $45 \%$ with more occurrences in women versus men [7]. Moreover a systematic review of published papers between 1990 and 2011 showed that overweight and obesity in all age groups of the EMR countries ranging from 25\% to $81.9 \%$ [8]. Literature shows that the prevalence of obesity in Iran 35\% [9], in Cyprus 28.8\% [10], in United States 30.5\% [11], in United Kingdom 23\% in men and 24\% in women [12]. The main factors associated with overweight and obesity were age, gender, residence, literacy, socio-economic status, dietary habits, physical inactivity, nutrition transition, marital status, breastfeeding, frequent snacking, skipping breakfast, intake of sugary beverages, the incidence of eating outside the home, frequency of viewing television, high fat foods, total serum cholesterol, low density lipoprotein, blood glucose, triglycerides, frequency of intake of fruits and vegetables, level of daily exercise, smoking and more [6-11,13].

In Afghanistan, due to years of war and conflict, few studies have been conducted to estimate the burden of obesity in the country. The in age groups with cutoff point 20 years are $6.8 \%$ and $14.8 \%$ in males and $4.4 \%$, and $13.8 \%$ in women [14]. According to literature the first ever study on overweight was conducted in 1997 in children $\leq 3$ years with the result of $4 \%$ prevalence [15]. In 2002 in a provincial study in Afghanistan the prevalence of obesity and overweight in adult females were $1.8 \%$ and $11.5 \%$ with average BMI of 21.1 $\mathrm{Kg} /$ meter square [16]. However recent studies in Kabul and Jalalabad the main big cities in Afghanistan showed that the prevalence of obesity in adult citizens were $31.2 \%$ and $27.4 \%$ respectively [17, 18]. Kandahar city is another big southern city in the country in which no data is available on overweight and obesity while due 
attention is given to infectious diseases, nutrition and maternal health. The main objective of this article is to identify and assess the prevalence and factors associated with obesity in Kandahar city Afghanistan.

\section{METHODS AND MATERIALS}

We conducted a survey using WHO STEP wise approach [19] to determine the burden of noncommunicable diseases in main cities of Afghanistan. In this study we included 1165 subjects to reflect the burden of obesity and its related factors in Kandahar city population targeting adult individuals in age group of 25-70 years of both sexes. Temporary residents (less than six months) and those living in institutionalized settings along with insecure areas were excluded from the survey. After statistical calculation, totally 1200 subjects enrolled in the study. Data was collected during October-November 2015. All permanent household members aged more than 25 years, including men and women who were residents of the cities during the study period and gave consent to participate were included in the study. Temporary residents (resident $<6$ months) and those living in institutionalized settings or insecure areas were excluded. Due to the unavailability of previous estimates of risk factor prevalence in this city we assumed the highest prevalence or sample size calculation (50\%), 95\% confidence interval (CI) and margin of error of 5\%. From this we estimated 385 subjects to be included in the survey. Taking into consideration the proportion of other risk factors in similar settings, the number of subjects was increased to 600 . Finally, after taking into account the design effect $(\mathrm{D}$ eff $=2)$ of cluster sampling the final sample size was increased to $(2 \times 600)=1200$ for the city, which was reasonable for achieving the study objectives with limited resources and funding support.

\section{Sampling Techniques and Strategy:}

As a framework the Expanded Programme for Immunization (EPI) list of the clusters was used due to its reliability in Ministry of Public Health. For the sample size, initially we obtained the list of all existed EPI clusters which included village/area name, population, and number of households per cluster. For this survey we used multi-stage cluster sampling. In the first stage, from this list we randomly selected 7 clusters of EPI using random number of excel sheet. In the second stage from each selected Cluster we randomly selected the five areas (called Area/Guzar). Later the overall sample of 1200 households distributed among these selected area according to the proportion to the size of household number in each cluster / areas. Finally, the number of households in each area divided by the sample size assigned for each areas, it was enable us to select household systematically.

\section{Data collection:}

According to the plan, two days training was conducted for surveyors followed by a field based session where participants had a chance to fill the questionnaire, measure hypertension and waist circumference and practice taking blood samples from adults under field conditions. A household was defined as a group of people who share the same food pot (not the same roof). In each household the interviewer enumerated all persons who were eligible for our study based on the inclusion criteria. In households with more than one eligible person, we used a lottery system to select the respondent for this survey. In cases of refusal, which was less than $5 \%$, the interviewer approached the next alternate household. This method provided an equal chance of each member of the household being selected. Various group of targeted data including demographic, behavioural and clinical variables were collected in Kandahar from October 28 to November 4, 2015 by direct interview using the WHO STEP-wise instrument. Anthropometric measurements (height and weight) were used to calculate body mass index (BMI). A BMI of $\geq 30 \mathrm{~kg} / \mathrm{m}^{2}$ was considered as obese, $25-30 \mathrm{~kg} / \mathrm{m}^{2}$ as overweight and $18.5-25 \mathrm{~kg} / \mathrm{m}^{2}$ as normal weight [20]. A waist circumference of $94 \mathrm{~cm}$ for men and $80 \mathrm{~cm}$ for women was considered as central obesity [21]. Systolic blood pressure $140 \mathrm{mmHg}$ and diastolic pressure $90 \mathrm{mmHg}$ were considered as hypertensive [22]. A fasting blood sugar of $\geq 126 \mathrm{mg} / \mathrm{dL}$ was considered as diabetes mellitus [23].

Following the interview blood samples were collected the next morning after the respondent had fasted for 1012 hours. Blood samples were transported in cool boxes $\left(2-8^{\circ} \mathrm{C}\right)$ from field to provincial public health directorate (PHD) Laboratory on the day of sample collection. After processing and separation the samples were shipped to Central Public Health Laboratory in Kabul in two consignments by air. Using Cry-vials the samples were coded with ID number of the questionnaire. On arrival in CPHL all serum samples were stored at $-80^{\circ} \mathrm{C}$ until biochemical test conducted. Altogether 1165 questionnaires and samples were filled and tested biochemical measurement of triglyceride, cholesterol, and glucose, except 12 samples which were poor and discarded. Afterwards they were shipped to the central public health laboratory in Kabul and stored at $-80^{\circ} \mathrm{C}$ for testing. Later, the biochemical measurement of blood lipid and sugar were conducted. Data were entered in Epiinfo, version 7, and cleaned data was analysed using SPSS, version 20 [24].

\section{Ethical Consideration}

The study protocol was approved by the institutional review board (IRB) of the Ministry of Public Health. After an explanation of the survey, informed consent was taken from each individual before the 
interview. The literate read and signed the informed consent while for illiterates the informed consent was read for interviewer and finger print was taken.

\section{RESULTS}

One thousand one hundred and sixty-five people were included in analysis after final cleaning of dataset and out of them $597(51.2 \%)$ were females and 568 (48.8\%) males with a mean age of $38.3 \pm 11.2$ years. More than two third (73.2\%) of the study participants were illiterates; $42 \%$ of the participants had income of less than 10000 AFN (USD150); 79.3\% were married and more than $88.5 \%$ of women were housewives. Proportion of cigarette smokers and mouth snuffers among study subjects were $9.7 \%$ and $16.7 \%$ respectively. More than half of study subjects $(59.7 \%)$ of respondents ate fruits less than 3 days per week and $40.3 \%$ ate vegetables less than three days per week. One third of study subjects (33.3\%) took solely liquid oil in their kitchen while $37 \%$ took solely solid oil for cooking. Approximately six percent (5.9\%) of study subjects performed strong physical activity and $21.3 \%$ of reported doing moderate physical activity. Table 1 shows the description of main factors collected and are associated with obesity. Using the traditional BMI cutoff values recommended by World Health Organization (WHO) the prevalence of underweight, normal weight, overweight, obesity grade I, obesity grade II and obesity grade III were $4.9 \%, 44.8 \%, 34.3 \%, 11.2 \%, 2.9 \%$ and $1.9 \%$ respectively. Figure 1 shows the spider graph of these proportions. As a combination more than half of the study subjects were overweight and obese while as a whole the prevalence of obesity was $16 \%$. Furthermore it seems that the prevalence of such overweight and obesity were higher in females versus males. This comparison is given in Figure 2 . The average body mass index as a whole was 25.71 while the mean and standard deviation (SD) or standard error of the mean (SEM) were increased by increasing the BMI. Table 2 shows the mean and SEM by categorization of BMI. Furthermore the average of total cholesterol, glycerides, high density lipoprotein, low density lipoprotein and fast blood sugar were $183 \mathrm{mg} / \mathrm{DL}, 154.65 \mathrm{mg} / \mathrm{DL}, 45.85 \mathrm{mg} / \mathrm{DL}, 107.3 \mathrm{mg} / \mathrm{DL}$ and 131mg/DL respectively. In another way we could say that level of cholesterol with cut off $190 \mathrm{mg} / \mathrm{dL}$ and level of triglyceride with cut off $150 \mathrm{mg} / \mathrm{dL}$ were categorized of them $30.4 \%$ had higher cholesterol and $35.7 \%$ had higher triglycerides. Furthermore, high level of low density lipoprotein (LDL) with cut of $100 \mathrm{mg} / \mathrm{dL}$ were $50.9 \%$ and high level of high density lipoprotein (HDL) were both $46.6 \%$. Table 3 shows the association of main risk factors and obesity for categorical variables. Age and gender both as non-modifiable variables were associated significantly with obesity. Males were 0.37 times less likely to be obese as compare to females (95\% CI: $0.26-0.52$ ). Odds of being obese was low in literate as compare illiterate $(\mathrm{OR}=0.35,95 \% \mathrm{CI}: 0.22-0.55)$. Furthermore, subjects who used mouth snuff were 0.50 times less likely to be obese as compare to nonusers $(95 \% \mathrm{CI}$ : $0.30-0.84)$ however we could not found any significant relationship of smoking with obesity. Physical activity at vigorous level was not significantly associated with obesity but moderate physical activity had relationship with obesity. It means that those who were practicing moderate physical activity were 1.65 times more likely to be obese as compare to those who were practicing less $(95 \% \mathrm{CI}: 1.16-2.36)$. Furthermore sedentary lifestyle was also associated significantly with obesity $(\mathrm{OR}=0.65,95 \% \mathrm{CI}: 0.48-0.90)$. Finally the pathophysiological factors such as high blood pressure $(\mathrm{OR}=1.94,95 \% \mathrm{CI}: 1.40-2.66)$ and central obesity (OR=3.66, 95\% CI: $2.48-5.41)$ were found to have significant relationship with obesity. The quantitative variables were such as age, gender, taking food outside, moderate physical activity, reclining in hours per day, walking for any reason, height, weight and level of triglyceride were significantly associated with obesity. The mean and SD with p values are shown in table 4. At multivariate model age at lower groups, gender, education level, level of triglycerides, walking time in hours per day, high blood pressure, central obesity were independently associated with obesity. Table 5 reflects the multivariate analysis using binary logistic regression.

\section{DISCUSSION}

The finding of this study shows that the prevalence of obesity in Kandahar city is $16 \%$ which is lower as compare to other cities of Afghanistan as well as other countries; however the proportion of overweight $(34.3 \%)$ were comparable with other studies [6, 17-18, 25-26]. Age and gender both at bivariate and multivariate level of analysis are affecting directly the level of obesity. It seems older age particularly females are at greater risk of higher weights which contributes to other communicable diseases it could be due to low physical activity at higher age groups as well as women are less physically active then men due to cultural context. Similar results regarding age and gender are reported by the studies conducted in a number of Middle East countries such as: Bahrain, Saudi Arabia, Lebanon as well as Pakistan. [26-31]. Illiteracy is high in Afghanistan and it is associated with obesity at both level of analysis. Probably it could means literate group are more health oriented and taking preventive measures and less likely to be obese as compare to illiterate. The health literacy and obesity are shown to have association in other studies [32]. Blood pressure was associated with obesity which shows the adult populations are suffering from different risk factors at the same time. The significant association of obesity and blood pressure are well reported by other studies as well [6, 17, and 18]. The more level of triglycerides were significantly associated with high level of obesity which make the person 
vulnerable to cardiovascular diseases. The relationship of plasma lipids with obesity is supported by other studies [33]. Walking as a proxy for physical activity was a factor associated with obesity which is consistent with many other studies [34-35]. At multivariate it we could not found any significant association of diet in terms of taking fruit, vegetables, rice, chicken and meat with obesity. Likewise the association of strong or moderate physical activity was not proved in this study. Beyond all these findings which could be used for formulating interventions we were limited to specific budget which as a constraint could not list all households ahead of study. Moreover some areas were excluded due to security concerns. Although the country has not fully defeated the vaccine preventable as well as other infectious diseases addition of noncommunicable public health problems such as overweight and obesity will challenge the health system with limited resources. Predominantly the concurrence of risk factors for noncommunicable diseases such as overweight and obesity, high blood pressure and diabetes will make conducive environment for high occurrence of double burden of diseases. The results of this study could encourage planners and policy makers to focus on interventions to prevent and control obesity in this urban setting of Afghanistan.

\section{ACKNOWLEDGEMENTS}

The main study was supported by financially by Ministry of Public Health and World Health Organization. WHO and Afghan National Public Health Institute is thanked for their financial and technical guidance. In addition we would like to thank all our technical supervisors, data collectors, study participants for their guidance and support of this study.

\section{REFERENCES}

[1] World Health Organization. Global strategy on diet, physical activity and health. Geneva: World Health Organization, 2004. http://www.who.int/dietphysicalactivity/en/

[2] Kottke, T.E, Wu, L.A, Hoffman, R.S. 2003. Economic and psychological implications of the obesity epidemic. Mayo.Clin. Proc.78, 92-94.

[3] Cawley, J. 2004. The impact of obesity on wages. J. Human. Resour. XXXIX, 451-474.

[4] Puhl, R. and Brownell, K.D. 2001. Bias, discrimination, and obesity. Obes. Res. 9, 788-805.

[5] Lim SS, Vos T, Flaxman AD, et al. A comparative risk assessment of burden of disease and injury attributable to 67 risk factors and risk factor clusters in 21 regions, 1990-2010: a systematic analysis for the Global Burden of Disease Study 2010. Lancet 2012; 380: 2224-60.

[6] Jafar TH, Chaturvedi N, Pappas G. Prevalence of overweight and obesity and their association with hypertension and diabetes mellitus in an Indo-Asian population. CMAJ 2006;175(9):1071-7

[7] Musaiger AO. Overweight and obesity in the Eastern Mediterranean Region: can we control it? Eastern Mediterranean Health Journal, Vol. 10, No. 6, 2004

[8] Musaiger AO, Overweight and Obesity in Eastern Mediterranean Region: Prevalence and Possible Causes. Journal of Obesity. 2011, Article ID 407237, pp. 1-17. doi:10.1155/2011/407237

[9] Veghari GR, et al. The prevalence of obesity and its related risk factor in the North of Iran in 2006. JRHS. 2010; 10 (2):116-121.

[10] Andreou E, et al. Risk factors of obesity in a cohort of 1001 Cypriot adults: An epidemiological study. HIPPOKRATIA 2012, 16, 3: 256-260

[11] Flegal KM, Carroll MD, Ogden CL, Johnson CL: Prevalence and trends in obesity among US adults, 1999-2000. JAMA 2002, 288:1723-1727.

[12] British Heart Foundation: Diet, Physical Activity and Obesity Statistics., 2006 http://www.heartstats.org/datapage. asp?id=5749.

[13] Haque et al. Prevalence and Risk Factors of Obesity and Hypertension among University Students in Rajshahi City, Bangladesh. Bangladesh Pharmaceutical Journal 19(2): 179-184, 2016

[14] Marie Ng et al. Global, regional, and national prevalence of overweight and obesity in children and adults during 1980-2013: a systematic analysis for the Global Burden of Disease Study 2013. www.thelancet.com Published online May 29, 2014 http://dx.doi.org/10.1016/S0140-6736(14)60460-8

[15] De Onis $M$ and Blossner $M$, Prevalence and trends of overweight among preschool children in developing countries. American Journal of Clinical Nutrition, vol. 72, no. 4, pp.1032-1039, 2000.

[16] Nutrition and Health Survey, Badghis Province, Afghanistan, February-March 2002 (IB Ref: 101440a1)

[17] Saeed KMI, Rasooly MH. Prevalence and Risk Factors Associated with Obesity among Adult Kabul Citizens (Afghanistan), 2012. Iranian Journal of Diabetes and Obesity (2012); 4(4): pp152-161

[18] Saeed KMI, Prevalence and associated risk factors for obesity in Jalalabad city - Afghanistan, Alex J Med (2015), http://dx.doi.org/10.1016/j.ajme.2014.12.004 
[19] Bonita R, de Courten M, Dwyer T, Jamrozik K, Winkelmann R. Surveillance of risk factors for noncommunicable disease: the WHO STEP wise approach. Geneva: World Health Organization; 2002. WHO document WHO/NMH/CCS/01.2002

[20] World Health Organization. Obesity: preventing and managing the global epidemic. Geneva: World Health Organization; 2000 (WHO Technical Report Series No.894)

[21] International Diabetes Federation: The IDF consensus worldwide definitions of the metabolic syndrome. Available online : http://www.idf.org/webdata/docs/IDF_Meta_def_final.pdf , 2006

[22] Whitworth JA. World Health Organization (WHO)/International society of Hypertension (ISH) statement on management of hypertension. J Hypertens 2003;21:1982-92

[23] World Health Organization. Diabetes. Fact sheet no. 312.Geneva: World Health Organization; 2015 (http://www.who.int/mediacentre/factsheets/fs312/en/.

[24] IBM SPSS Statistics for Windows [computer program]. Version 20.0. Armonk, NY: IBM Corporation; 2011.

[25] AkramGhadiri-Anari A, et al. Prevalence of Obesity and Overweight among Adults in Iranian Population (Yazd Province). Iranian journal of diabetes and obesity. 2013; 5 (2):67-70.

[26] Mirzazadeh A, Sadeghirad B, Haghdoost AA, Bahrein F, Rezazadeh M. The prevalence of Obesity in Iran in Recent Decade; A Systematic Review and Meta-Analysis Study. Iranian J Publ Health 2009; 38(3):1-11.

[27] Yalcin BM, Sahin EM, Yalcin E. Prevalence and epidemiological risk factors of obesity in Turkey. Middle East Journal of Family Medicine, 2004; Vol. 6 (6)

[28] Musaiger AO, Al-Mannai MA. Weight, height, body mass index and prevalence of obesity among the adult population in Bahrain. Ann Hum Biol. 2001; 28:346-350.

[29] Ayatollahi S. M, Ghoreshizadeh T Z. Prevalence of obesity and overweight among adults in Iran. Obesity reviews 2010; 11: 335-337.

[30] Al-Nuaim AA, Bamgboye EA, al-Rubeaan KA, al-Mazrou Y. Overweight and obesity in Saudi Arabian adult population, role of sociodemographic variables. J Community Health. 1997; 22 (3):211-223.

[31] Sibai AM, Hwalla N, Adra N, Rahal B. Prevalence of and covariates of obesity in Lebanon: finding from the first epidemiological study. Obes Res 2003; 11:1353-61.

[32] Lam LT, Yang L. Is low health literacy associated with overweight and obesity in adolescents: an epidemiology study in a 12-16 years old population, Nanning, China, 2012? Arch Public Health. 2014 Apr 1; 72(1):11. doi: 10.1186/2049-3258-72-11.

[33] Despres JP, et al. Relation of high plasma triglyceride levels associated with obesity and regional adipose tissue distribution to plasma lipoprotein-lipid composition in premenopausal women. 1989, Clin Invest Med. 12(6):374-80

[34] Gutierrez-Fisac JL, et al. Work- related physical activity is not associated with body mass index and obesity. Obes Res 2002; 10:270-6.

[35] Lahti-Koski M, Pietinen P, Heliovaara M, Vartiainen E. Association of body mass index and obesity with physical activity, food choices, alcohol intake and smoking in the 1982-1997. Am J ClinNutr. 2002; 75:809-17.

Figure 1: Graphic Presentation of each category of body mass index 


\section{Proportions}

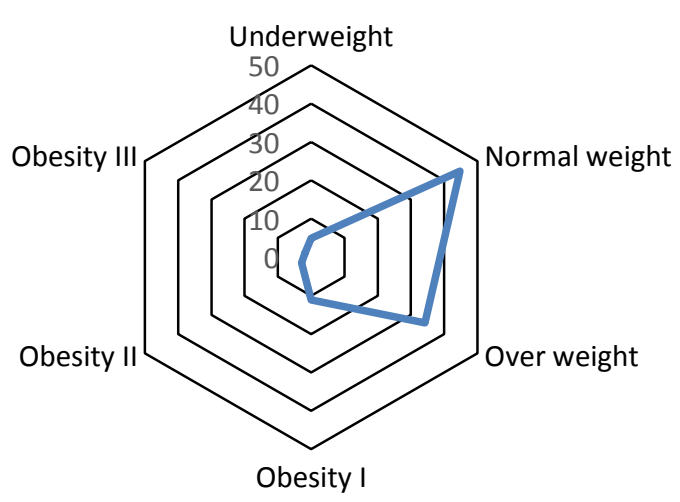


Figure 2: Graphic presentation of BMI categories by sex

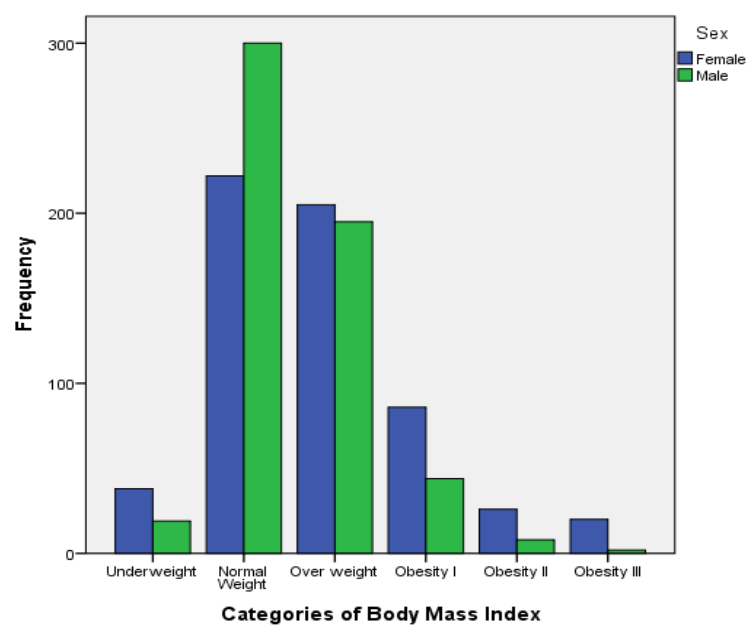

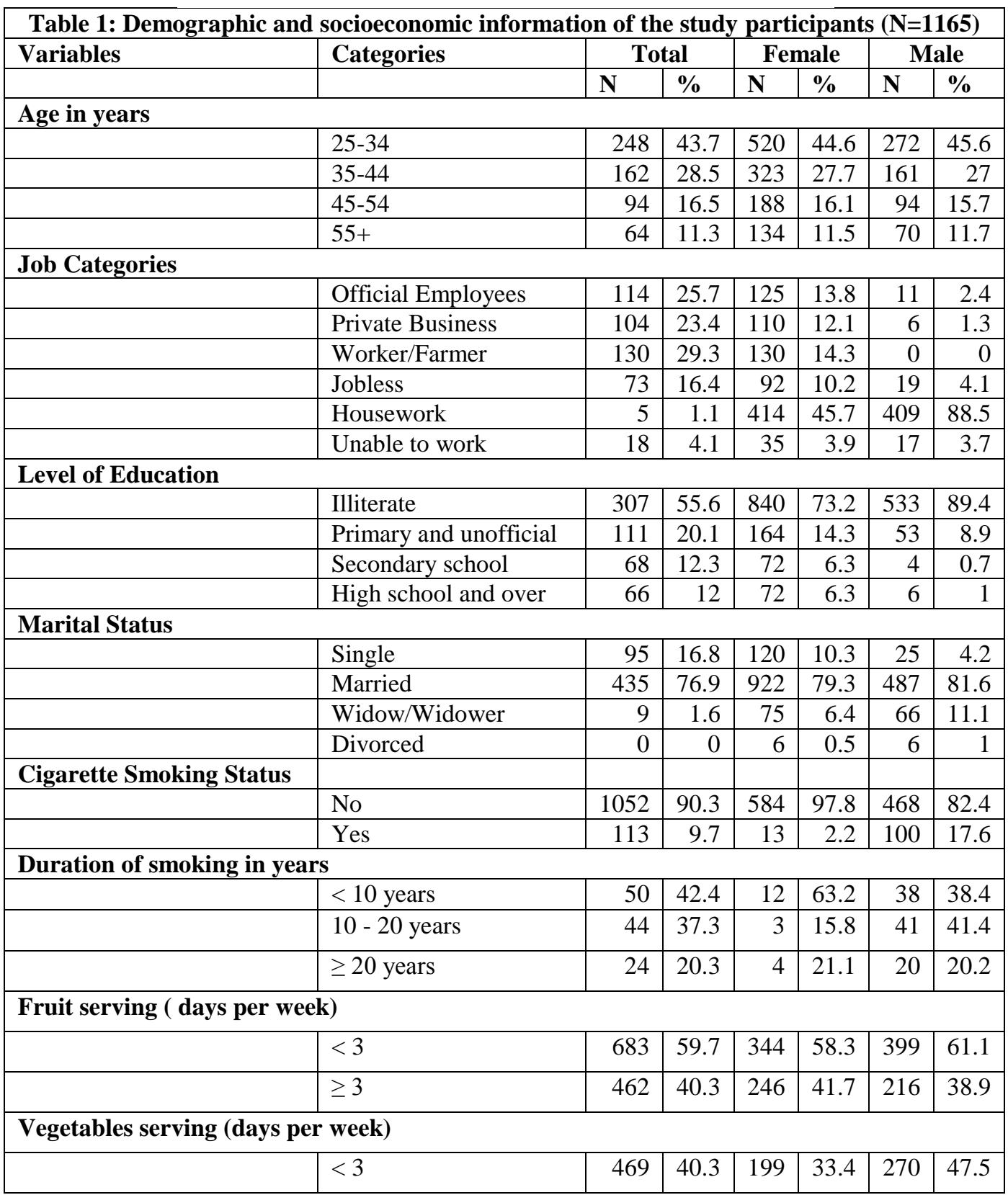


Obesity in Adults: A Neglected Public Health Problem in Urban Areas of Kandahar City-Afghanistan

\begin{tabular}{|c|c|c|c|c|c|c|c|}
\hline & $\geq 3$ & 695 & 59.7 & 397 & 66.6 & 298 & 52.5 \\
\hline \multicolumn{8}{|l|}{ Type of Kitchen Oil } \\
\hline & Liquid & 380 & 33.3 & 151 & 25.7 & 229 & 41.3 \\
\hline & Solid & 423 & 37 & 266 & 45.3 & 157 & 28.3 \\
\hline & Both & 339 & 29.7 & 170 & 29 & 169 & 30.5 \\
\hline \multicolumn{8}{|l|}{ Vigorous Physical Activity } \\
\hline & No & 1094 & 94.1 & 581 & 97.6 & 513 & 90.5 \\
\hline & Yes & 68 & 5.9 & 14 & 2.4 & 54 & 9.5 \\
\hline \multicolumn{8}{|l|}{ Moderate Physical Activity } \\
\hline & No & 914 & 78.7 & 434 & 72.9 & 480 & 84.8 \\
\hline & Yes & 247 & 21.3 & 161 & 27.1 & 86 & 15.2 \\
\hline
\end{tabular}

\begin{tabular}{|l|l}
\hline Table 2: Decretive statistics of BMI Categories for survey population \\
\hline
\end{tabular}

\begin{tabular}{|c|c|c|c|c|}
\hline BMI Categories & Age Group & Number & Mean & SEM \\
\hline \multirow[t]{5}{*}{ Underweight } & $25-34$ & 27 & 16.8295 & 0.25083 \\
\hline & $35-44$ & 12 & 16.9533 & 0.34264 \\
\hline & $45-54$ & 8 & 16.7168 & 0.50165 \\
\hline & $55+$ & 10 & 17.2046 & 0.31561 \\
\hline & Total & 57 & 16.9055 & 0.1623 \\
\hline \multirow[t]{5}{*}{ Normal weight } & $25-34$ & 268 & 22.0875 & 0.1003 \\
\hline & $35-44$ & 127 & 22.3841 & 0.13981 \\
\hline & $45-54$ & 77 & 22.3436 & 0.19117 \\
\hline & $55+$ & 50 & 22.1716 & 0.24282 \\
\hline & Total & 522 & 22.2055 & 0.07176 \\
\hline \multirow[t]{5}{*}{ Overweight } & $25-34$ & 169 & 27.1387 & 0.10572 \\
\hline & $35-44$ & 116 & 27.5802 & 0.12165 \\
\hline & $45-54$ & 69 & 27.3012 & 0.16562 \\
\hline & $55+$ & 46 & 27.7509 & 0.20255 \\
\hline & Total & 400 & 27.3652 & 0.06853 \\
\hline \multirow[t]{5}{*}{ Obese } & $25-34$ & 56 & 34.1843 & 0.67737 \\
\hline & $35-44$ & 68 & 35.241 & 0.99556 \\
\hline & $45-54$ & 34 & 33.8964 & 0.54903 \\
\hline & $55+$ & 28 & 35.5117 & 1.04271 \\
\hline & Total & 186 & 34.7178 & 0.45629 \\
\hline \multirow[t]{5}{*}{ Total } & $25-34$ & 520 & 24.7588 & 0.21119 \\
\hline & $35-44$ & 323 & 26.7552 & 0.36156 \\
\hline & $45-54$ & 188 & 26.0131 & 0.36371 \\
\hline & $55+$ & 134 & 26.5037 & 0.54052 \\
\hline & Total & 1165 & 25.7154 & 0.16387 \\
\hline
\end{tabular}

Table 3: Statistical analysis of bio demographic and socio-economic factors and obesity in survey population, Kandahar city

\begin{tabular}{|l|l|l|l|r|r|r|r|}
\hline Questions & Categories & Non-obese & Obese & Odds Ratio & CI 95\% LL & CI 95\% UL \\
\hline Age in years \\
\hline
\end{tabular}


Obesity in Adults: A Neglected Public Health Problem in Urban Areas of Kandahar City-Afghanistan

\begin{tabular}{|c|c|c|c|c|c|c|}
\hline \multicolumn{7}{|c|}{ Level of education } \\
\hline & Illiterate & $682(81.2)$ & $158(18.8)$ & 1 & \multicolumn{2}{|c|}{ Reference } \\
\hline & Literate & $285(92.5)$ & $23(7.5)$ & 0.348 & 0.22 & 0.551 \\
\hline \multicolumn{7}{|l|}{ Smoking } \\
\hline & No & $877(83.4)$ & $175(16.6)$ & 1 & \multicolumn{2}{|c|}{ Reference } \\
\hline & Yes & $102(90.3)$ & $11(9.7)$ & 0.54 & 0.284 & 1.028 \\
\hline \multicolumn{7}{|l|}{ Snuffing } \\
\hline & No & $806(82.8)$ & $167(17.2)$ & 1 & \multicolumn{2}{|c|}{ Reference } \\
\hline & Yes & $171(90.5)$ & $18(9.5)$ & 0.508 & 0.304 & 0.849 \\
\hline \multicolumn{7}{|c|}{ Strong Physical Activity } \\
\hline & No & $925(84.6)$ & $169(15.4)$ & 1 & \multicolumn{2}{|c|}{ Reference } \\
\hline & Yes & $52(76.5)$ & $16(23.5)$ & 1.684 & 0.939 & 3.019 \\
\hline \multicolumn{7}{|c|}{ Moderate Physical Activity } \\
\hline & No & $782(85.6)$ & $132(14.4)$ & 1 & \multicolumn{2}{|c|}{ Reference } \\
\hline & Yes & $193(78.1)$ & $54(21.9)$ & 1.658 & 1.164 & 2.361 \\
\hline \multicolumn{7}{|c|}{ Sedentary lifestyle in hours daily } \\
\hline & $<3$ hours & $409(81)$ & $96(19)$ & 1 & \multicolumn{2}{|c|}{ Reference } \\
\hline & $\geq 3$ hours & $564(86.6)$ & $87(13.4)$ & 0.657 & 0.479 & 0.902 \\
\hline \multicolumn{7}{|c|}{ Fruits serving days per week } \\
\hline & $<3$ days & $569(83.3)$ & $114(16.7)$ & 1 & \multicolumn{2}{|c|}{ Reference } \\
\hline & $\geq 3$ days & $392(84.8)$ & $70(15.2)$ & 0.891 & 0.644 & 1.233 \\
\hline \multicolumn{7}{|c|}{ Vegetables serving days per week } \\
\hline & $<3$ days & $399(85.1)$ & $70(14.9)$ & 1 & \multicolumn{2}{|c|}{ Reference } \\
\hline & $\geq 3$ days & $579(83.3)$ & $116(16.7)$ & 1.142 & 0.827 & 1.577 \\
\hline \multicolumn{7}{|c|}{ High Blood Pressure } \\
\hline & No & $687(87.1)$ & $102(12.9)$ & 1 & \multicolumn{2}{|c|}{ Reference } \\
\hline & Yes & $292(77.7)$ & $84(22.3)$ & 1.938 & 1.408 & 2.667 \\
\hline \multicolumn{7}{|c|}{ Total Cholesterol } \\
\hline & $<190 \mathrm{mg} \%$ & $688(85.8)$ & $114(14.2)$ & 1 & \multicolumn{2}{|c|}{ Reference } \\
\hline & $\geq 190 \mathrm{mg} \%$ & $283(80.6)$ & $68(19.4)$ & 1.45 & 1.042 & 2.018 \\
\hline \multicolumn{7}{|c|}{ Central Obesity } \\
\hline & No & $446(92.5)$ & $36(7.5)$ & 1 & Reference & \\
\hline & Yes & $463(77.2)$ & $137(22.8)$ & 3.666 & 2.483 & 5.411 \\
\hline
\end{tabular}

\begin{tabular}{|l|l|r|r|r|r|}
\hline \multicolumn{2}{|c|}{$\begin{array}{c}\text { Table 4: Descriptive characteristics of quantitative variables and obesity in survey population in } \\
\text { Kandahar city }\end{array}$} \\
\hline \multirow{2}{*}{ Variables } & \multicolumn{1}{|c|}{ Obesity } & \multicolumn{1}{c|}{ N } & \multicolumn{1}{c|}{ Mean } & \multicolumn{1}{c|}{ SD } & \multicolumn{1}{c|}{ P values } \\
\hline \multirow{2}{*}{ Age in years } & No & 979 & 37.93 & 11.277 & 0.005 \\
\cline { 2 - 6 } & Yes & 186 & 40.45 & 10.997 & 0.005 \\
\hline \multirow{2}{*}{ Fruits taking days per week } & No & 961 & 3.35 & 1.619 & 0.784 \\
\cline { 2 - 6 } & Yes & 184 & 3.31 & 1.889 & 0.805 \\
\hline \multirow{2}{*}{ Vegetables taking days per week } & No & 978 & 3.94 & 1.683 & 0.532 \\
\cline { 2 - 6 } & No & 186 & 4.02 & 1.786 & 0.549 \\
\hline \multirow{2}{*}{ Red meat taking days per week } & Yes & 951 & 1.79 & 1.176 & 0.368 \\
\cline { 2 - 6 } & No & 178 & 1.7 & 1.082 & 0.342 \\
\hline \multirow{2}{*}{ Chicken taking days per week } & Yes & 944 & 1.41 & 0.943 & 0.534 \\
\cline { 2 - 6 } & No & 173 & 1.46 & 0.905 & 0.523 \\
\hline \multirow{2}{*}{ Rice taking rice days per week } & Yes & 963 & 2.72 & 1.303 & 0.212 \\
\cline { 2 - 6 } & No & 182 & 2.59 & 1.559 & 0.270 \\
\hline Taking food outside home day per week & No & 712 & 0.87 & 1.573 & 0.003 \\
\cline { 2 - 6 } & Yes & 115 & 0.42 & 1.034 & 0.000 \\
\hline Strong physical activity days per week & No & 50 & 4.14 & 1.895 & 0.544 \\
\hline
\end{tabular}


Obesity in Adults: A Neglected Public Health Problem in Urban Areas of Kandahar City-Afghanistan

\begin{tabular}{|l|l|r|r|r|r|}
\hline & Yes & 14 & 3.79 & 2.007 & 0.561 \\
\hline Moderate physical activity days per week & No & 181 & 2.83 & 1.414 & 0.865 \\
\cline { 2 - 5 } & Yes & 53 & 2.87 & 1.687 & 0.878 \\
\hline Moderate physical activity hours per day & No & 181 & 1.98 & 1.491 & 0.022 \\
\cline { 2 - 5 } & Yes & 54 & 2.69 & 3.107 & 0.111 \\
\hline \multirow{2}{*}{ Pedal or bicycle riding hours per day } & No & 805 & 1.79 & 3.197 & 0.039 \\
\cline { 2 - 5 } & No & 141 & 2.4 & 3.533 & 0.056 \\
\hline Reclining hours per day & Yes & 973 & 4.39 & 2.465 & 0.003 \\
\cline { 2 - 6 } & No & 183 & 3.8 & 2.228 & 0.001 \\
\hline Walking (any reasons) in hours per day & Yes & 945 & 7.83 & 14.248 & 0.047 \\
\cline { 2 - 6 } & No & 184 & 10.09 & 13.575 & 0.041 \\
\hline \multirow{3}{*}{ Height in centimeters } & Yes & 979 & 166.59 & 11.15 & 0.000 \\
\cline { 2 - 6 } & No & 186 & 153.85 & 14.846 & 0.000 \\
\hline Weight in kilogram & Yes & 979 & 66.63 & 11.372 & 0.000 \\
\cline { 2 - 6 } & No & 186 & 81.15 & 11.029 & 0.000 \\
\hline Triglyceride & No & 971 & 151.77 & 89.087 & 0.019 \\
\cline { 2 - 6 } & No & 182 & 170.01 & 128.678 & 0.068 \\
\hline Cholesterol & Yes & 971 & 181.88 & 51.552 & 0.087 \\
\cline { 2 - 6 } & No & 182 & 189.27 & 62.635 & 0.135 \\
\cline { 2 - 6 } & No & 182 & 121.83 & 95.843 & 0.146 \\
\hline
\end{tabular}

\begin{tabular}{|c|c|c|c|c|c|c|}
\hline Variables & Categories & B & $\operatorname{Exp}(B)$ & $\begin{array}{l}\text { CI 95\% Lower } \\
\text { Limit }\end{array}$ & $\begin{array}{l}\text { CI 95\% Upper } \\
\text { Limit }\end{array}$ & P Value \\
\hline \multicolumn{7}{|c|}{ Age group in years } \\
\hline & $25-34$ & & 1 & \multicolumn{3}{|c|}{ Reference } \\
\hline & $35-44$ & 0.609 & 1.838 & 1.102 & 3.065 & 0.02 \\
\hline & 45-54 & 0.013 & 1.013 & 0.542 & 1.896 & 0.967 \\
\hline & 55 and more & 0.472 & 1.603 & 0.841 & 3.055 & 0.151 \\
\hline \multicolumn{7}{|l|}{ Sex } \\
\hline & Male & & 1 & \multicolumn{3}{|c|}{ Reference } \\
\hline & Female & 0.521 & 1.684 & 1.002 & 2.831 & 0.049 \\
\hline \multicolumn{7}{|c|}{ Education Status } \\
\hline & Literate & & 1 & \multicolumn{3}{|c|}{ Reference } \\
\hline & Illiterate & 0.849 & 2.337 & 1.236 & 4.418 & 0.009 \\
\hline \multicolumn{2}{|c|}{ Triglycerides } & 0.004 & 0.644 & 0.412 & 1.005 & 0.053 \\
\hline Walking in & day & 0.078 & 1.082 & 1.024 & 1.142 & 0.005 \\
\hline \multicolumn{7}{|c|}{ High blood pressure } \\
\hline & Yes & & 1 & \multicolumn{3}{|c|}{ Reference } \\
\hline & No & -0.44 & 0.053 & 0.644 & 0.412 & 0.000 \\
\hline \multicolumn{7}{|c|}{ Central Obesity } \\
\hline & Yes & & 1 & \multicolumn{3}{|c|}{ Reference } \\
\hline & No & -1.262 & 0.283 & 0.158 & 0.508 & 0.000 \\
\hline
\end{tabular}

